\title{
The Course Construction Study of the Principles of Accounting Under the Background of "Student- Centered"
}

\author{
$\mathrm{Su} \mathrm{Bo}^{*}$ Li Lingshan ${ }^{1}$ Dong Jiayin ${ }^{2}$
}

\begin{abstract}
* School of Management, Hubei University of Traditional Chinese Medicine
${ }^{1}$ School of Management, Hubei University of Traditional Chinese Medicine

${ }^{2}$ School of Management, Hubei University of Traditional Chinese Medicine

Author.Email:DongJiaying0904@163.com.
\end{abstract}

\begin{abstract}
The educational concept of "student-centered" is developing rapidly in the curriculum construction of colleges and universities at home and abroad, and this paper will study the teaching model of "student-centered" from the colleges and universities teaching and take the Principles of Accounting as the researches object The Principles of Accounting is the foundation course of accounting major and even economic management major, and the construction of studentcentered accounting principle curriculum should have the characteristics of educational idea innovation, teaching mode innovation, teaching content and system innovation, teaching method innovation, etc. And it should be implemented from whether the teaching model runs through the student subject status, whether the teaching content is conducive to cultivating college students in the new era, whether the teaching method matches the learning ability of college students, whether the construction of teaching materials conforms to the learning characteristics of college students and so on, which is based on the comprehensive integration of "student-centered" concept.
\end{abstract}

Keywords: student-centered, the principles of accounting, practical teaching, teaching evaluation

\section{“以学生为中心” 背景下《会计学原理》课程建设研 究} 苏波 ${ }^{*}$ 李灵珊 ${ }^{1}$ 董佳音 $^{2}$

*湖北中医药大学管理学院

${ }^{1}$ 湖北中医药大学管理学院

2 湖北中医药大学管理学院

2DongJiaying0904@163.com

摘要

“以学生为中心” 教育理念在国内外高校课程建设中发展较快, 本文将从高校教学层面研究 “以学生为中心” 的教学模式, 以《会计学原理》课程为研究对象进行探索。《会计学原理》是会计专业乃至经济管理类专业的 基础课, 以学生为中心的会计学原理课程建设应具有教育理念创新、教学模式创新、教学内容体系创新、教学 方法创新等特色; 应在全面融入 “以学生为中心” 理念的基础上, 从教学模式是否贯穿学生主体地位、教学内 容是否有利于培养新时代大学生、教学方式是否匹配大学生学习能力、教材建设是否符合大学生学习特点等方 面来实施。

关键词: 以学生为中心; 会计学原理; 实践教学; 教学评价 


\section{1. 前言}

《会计学原理》是经济管理类的专业基础课, 其 教学质量直接影响到后续其他专业课程的学习质量。 “以学生为中心”的教育理念提倡尊重学生的主体性, 在此理念下, 教师变为组织参与者。在教学过程中, 不是学生服从教师的安排, 而是教师根据学生兴趣来 设置教学内容。“以学生为中心”的教育理念使得教师 教学模式更加灵活、学生成为教学中的主角, 这将有 助于提高课堂活跃度和学生学习及探索新知识的积 极性, 有助于提高教学质量, 为社会发展输送综合素 质高、胜任能力强的专业人才。

\section{2. 《会计学原理》教学模式的选择一讨论 式}

教学模式应该贯穿以学生为主体地位的学习全 过程。在日常的教学实践中, 教师们也应该在常用的 讲授式、启发式、讨论式等几种教学模式上进行适当 的时间比例分配, 增加启发式特别是讨论式教学模式 的使用。而且, 在以往的课程实践中, 讨论式教学以 其较多的关注学生主体地位的优势受到了更多教师 和同学们的青睐。

\section{1. 讨论式教学的重要意义}

习近平总书记提出: 对高校来讲, 就是要坚持以学 生为中心, 把学生对成长成才的追求作为奋斗目标, 切实做到 “围绕学生、关照学生、服务学生”, 努力将 学生培养成为志存高远、德才兼备、全面发展的社会 主义事业合格建设者和可靠接班人。《会计学原理》作 为经济管理专业大学生必修的专业基础课, 在其教学 过程中也应打破纯粹的讲授式教学, 积极实行讨论式 教学, 为学生的全面素质教育服务 ${ }^{[1]}$ 。

\section{1. 1. 《会计学原理》课程中讨论式教学的 实践}

\subsubsection{1. 讨论准备}

教师首先应该做的是讨论问题的选择，选择的问 题既不能太复杂，也不能太简单，同时也不能理论性 太强, 不能违背讨论式教学的初衷, 要有利于学生创 新思维和学习能力的培养。《会计学原理》课程中并非 所有的问题都可以采用讨论式教学模式, 应酌情考虑。 第二点是讨论形式的选择, 即课上讨论或者课后讨论 的选择, 这需要考虑讨论学习内容的重要性和需要的 时间长度, 若较为重要则采用课上讨论, 若所需时间 较长, 则建议采用课下讨论的形式。第三点是小组成 员结构的分配，一般常见的分配方法有按照学号和按 照成绩编排小组。比如给学生讨论的主题是资产负债 表的编制目的和财务指标分析, 这个问题需要有会计 知识基础并且需要有一定的归纳总结能力, 任务难度 为中等偏上。由于资产负债表的编制涉及到之前学习 的资产、负债等方面的内容, 从某种程度上来说学生 会有更多的兴趣, 拿到题目就会有一定的讨论方向和 目标。

\subsubsection{2. 展开讨论}

在讨论过程中教师需要关注学生的执行动态, 考 察每个小组每一个阶段所完成的任务、遇到的问题、 分析问题的思路、解决问题的能力, 以及小组成员的 沟通协调能力等。同时还要发挥教师的引导作用, 对 于讨论出现偏差的小组及时进行提示 [1]。比如讨论资 产负债表的编制时，在资产和负债范围的界定、货币 资金与流动负债的关系等关键的问题上，教师应该对 应该对各个小组是否达成一致以及没有达成一致的 小组中出现的问题进行观察处理, 这将对后续的教学 产生具有针对性指导作用。

\subsubsection{3. 讨论交流}

交流时各小组分享自己小组的观点, 同时在这个 环节中提示同学们注意观察其他小组的活动情况, 提 升互相学习、取长补短的能力。

\subsubsection{4. 《会计学原理》课程实践流程图}

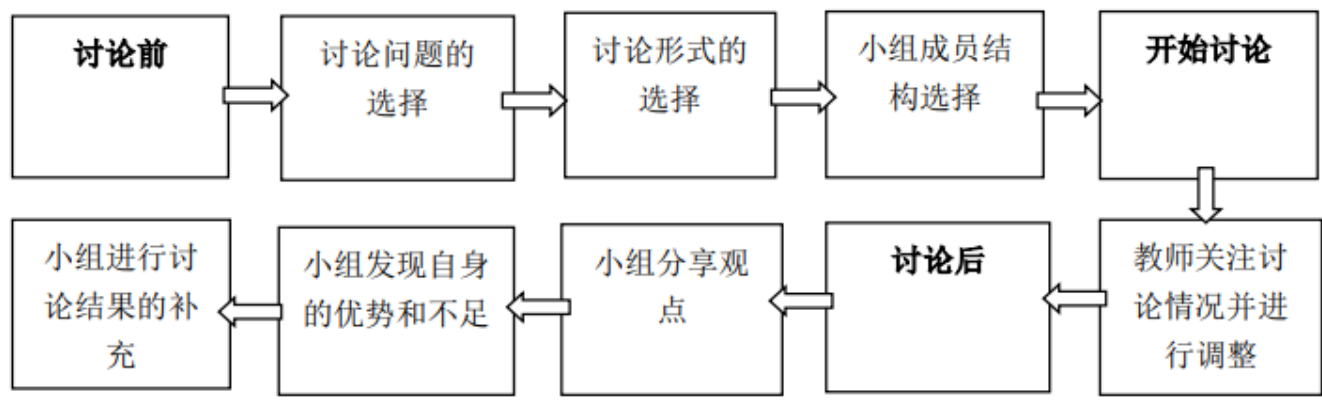

图 1 课程实践流程图 


\section{3. 以学生为中心选择新型教学模式一网络 教学模式}

近年来，随着网络信息技术的发展，传统的以课 堂教学为主的教学模式由于教学资源不够丰富, 理论 和实践相脱离、师资力量不足等, 限制了学生实践能 力的培养与提高 ${ }^{[3]}$ 。网络教学作为一种全新的教学模 式, 适应了当代大学生的学习生活特点, 符合以学生 为中心的教学理念, 必将深刻地影响高校的教学改革 [2]。

\section{1. 网络教学模式的内涵}

网络教学模式是互联网快速发展而产生的新型 教学模式, 具有多元化、综合化、多样化和扩大化的 特点。网络环境下的教学是以网络为教学平台, 形成 教师与学生之间的稳定关系和活动进行形式。网络教 学模式的独特优势在于, 在互联网教学平台上它仍然 可以强调以学生为中心, 重塑教学的结构形式, 建立 学生的主体学习地位、教师的引导角色、教学设计多 样性的教学体系。网络教学模式不仅可以充分发挥互 联网的优势, 提高学生的学习热情和兴趣, 还可以有 效提高学习效果。

\section{2. 网络教学模式应用的意义}

教师在授课过程中会用问卷星、雨课堂等软件进 行辅助教学, 并充分利用线上课程一慕课、网易公开 课对学生学习的内容进行巩固。慕课、网易公开课具 有课程门类齐全、课程质量高、学习便捷等特点, 常 常受到自学爱好者的青睐, 有利于弥补由于课程内容 过多, 学生较难整合知识点的缺陷, 此外, 多样化的 教学方式有利于提高学生学习的持续性, 对课程的评 价标准也会更丰富多样, 便于教师对课程的改进和完 善。

\section{4. 《会计学原理》教学内容的选择}

教学内容应该注重理论和实践的结合。理论的学 习有利于学生实践的完成, 实践的学习有利于学生对 理论的理解, 二者相辅相成。

\section{1. 传统会计学原理课程两大教学内容}

传统的《会计学原理》课程教学内容包括会计理 论和会计实务两部分, 会计理论部分的教学内容以会 计的含义为起点, 介绍了会计的基本理论, 围绕借贷 记账法重点说明了工业企业的会计业务处理。会计实 务部分主要介绍企业会计的基本手工操作实务。因此, 《会计学原理》课程既要求学生掌握借贷记账法的基 本应用, 还重点强调企业会计手工实务的操作 ${ }^{[4]}$ 。

\section{2. 实践学时的增加有利于综合素质的培养}

《会计学原理》课程除了要把会计基本的理论、 基础知识和会计核算的基本程序和技能传授给学生, 还要注重学生动手能力的训练, 重视会计应用能力的 提升。在课堂内外均要体现理论与实践并重, 理论学 习之余, 教师可以带领学生进行会计事务所的参观学 习。另外, 由于计算机的普及和对计算机应用能力要 求的不断提高, 在会计学原理课程中加入利用 EXCEL 进行会计核算的内容成为了必然要求, 让学 生可以利用 EXCEL 进行凭证的填制、账簿的登记以 及报表的编制, 这也将会为后续会计智能化的学习打 下良好的基础。此外，教师还可以利用沙盘进行财务 活动的模拟, 给学生提供一个尽可能真实的财务场景。

\section{5. 《会计学原理》教材的选择}

\section{1. 教材选择应结合当代思政教育原则}

教学活动应以培养学生正确的世界观、价值观为 基础, 思政教育的建设对于高校教学活动来说更是根 基。因此，在教材的选择上，应该首选国家规划教材。 此外, 我们也可以参考《会计学原理》国家精品课程 教材及其他教学资源, 并鼓励教师结合自己教学经历, 形成教学讲义甚至出版专业教材 ${ }^{[5]}$ 。

\section{2. 教材选择应遵循培养有特色的财务人原 则。}

我们应该结合各院校特色选择最适宜的教材, 立 足于院校特色有利于发挥学生特长, 培养出行业所需 要的具有相关领域专业知识的综合性人才。例如医药 院校应选择具有医药行业背景知识的教材, 医药院校 的经管类专业学生最好选择中国人民卫生出版社相 关的经济管理教科书, 有利于培养与医疗卫生单位具 有更高更深切合度的经济专业人才。

\section{6. 《会计学原理》课程改革配套保障制度}

\section{1. 配套措施实施的意义}

由于课堂建设具有一定的复杂性, 各种不确定因 素较多, 所以我们需要一系列较为完善的课堂管理措 施进行保障。以《会计学原理》课程为例, 课堂小组 讨论编制资产负债表会导致一定程度上的课堂秩序 混乱和部分学生学习覆盖面较低的问题。“以学生为 中心” 的教学模式在提高学生能力上较为明显, 但较 难保证教学内容的传递是否准确。以上一些问题的存 在, 要求具有相应的配套措施进行保障。

\section{2. 保障措施的制定和实施流程}

完整的保障措施应包括项目前期的沟通与制度 安排保障、总体问题解决方案的制定、常见具体问题 
相应的解决措施、特殊问题应急解决办法和保障措施 实施成效评价五个方面。

以《会计学原理》为例, 在具体落实项目之前, 应建设由同一门课程教师组成的 “智囊团”, 专门提供 该课程具体实施中可能出现的问题的解决办法, 同时 争取得到学校管理部门的政策扶持和经费支持也很 有必要; 问题的总体解决方案为 “自我解决” 办法, 即学生自己解决自己的课制造堂问题。“智囊团”讨论 教学前期、中期和后期各阶段可能出现的问题, 并对 这些问题制定方案。例如: 为保证课堂秩序, 建立课 程学习小组维护课程秩序的任务; 为检测学习效果, 学生应定期上交学习报告和给予教师授课建议。

\section{7. 结论}

在 “以学生为中心” 的教学理念指导下进行 《会 计学原理》课程建设, 重新建设学生主体地位的教学 模式、构建符合新时代大学生的教学内容、选择提升 大学生学习能力的教学方式和学习特点的专业教材, 将是新时代高校教育《会计学原理》课程建设的新要 求, 将有利于提高学生学习的学习能动性, 提高打学 生的综合素质。

\section{基金项目}

本文系 2020 年湖北高校省级教学研究项目 (2020535) “课程思政视域下经济管理类课程金课建 设的路径研究” 的主要成果。

\section{REFENCES}

[1] Liu Jiangrong. Discussion and practice of discussion teaching in university mathematics[J]. Neijiang Science and Technology, 2015, 36(10): 62-63.

[2] Liu Yuchun. Research on the problems and countermeasures of network teaching in ordinary colleges and universities[J]. Journal of Inner Mongolia Normal University (Education Science Edition), 2017, 30(10):132-135. DOI:10.3969/j.issn.1671- 0916.2017.10.025.

[3] Teaching thinking of basic accounting courses under the network teaching environment $[\mathrm{J}]$. China Management Information Technology, 2009,12(20):120-121.DOI:10.3969/j.issn.16730194.2009.20.045.

[4] Wang Wei, Gao Xin. Comparison and Integration of Accounting Professional Courses Teaching Contents in China and Foreign Countries_— Take the "Basic Accounting" course in the ISEC project as an example [J]. Commercial Accounting, 2015, (8): 114-115.

[5] Liu Jiansheng. Thoughts and Practice on the Construction of Excellent Courses of "Accounting Principles"[J]. China Electric Power Education, 2011, (31): 121-122,129. DOI:10.3969/j.issn.10070079.2011.31.060. 